\title{
INDÚSTRIA CULTURAL: BOURDIEU E A TEORIA CLÁSSICA
}

Indústria cultural, cultura de massa, campos, habitus e poder simbólico: conceitos importantes para se entender melhor a relação dos meios de comunicação com a sociedade

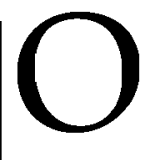

propósito deste artigo é levantar alguns pontos de convergência e de divergência entre Adorno/Horkheimer, Morin e Bourdieu no tocante ao fenômeno midiático. Nossa intenção não é fazer uma análise exaustiva das contribuições destes autores. O objetivo consiste em analisar especificamente o livro Sobre a televisão ${ }^{1}$, apontar a atualidade do debate a respeito da indústria cultural segundo a definição de Adorno/Horkheimer ${ }^{2}$ e Morin ${ }^{3}$ e a relevância das contribuições de Bourdieu ao introduzir na discussão o conceito de poder simbólico. Considero que a sociologia da mídia concebida por Bourdieu é tri- butária do pensamento desses autores, embora encontremos divergências importantes em suas obras.

Para desenvolvermos o argumento vamos destacar inicialmente as semelhanças entre os autores, trabalhando principalmente com suas convergências teóricas. Em um segundo momento, procederemos às diferenças no sentido de apontar as especificidades de cada uma das contribuições. Para a conclusão, reservaremos a discussão sobre o conceito de poder simbólico, pois acreditamos que este conceito encerra a atualidade do tema.

Sabe-se que a produção em caráter industrial dos bens da cultura data da déca-

\footnotetext{
1. BORDIEU, Pierre. Sobre a Televisão. Seguido de A Influência do Jornalismo e Os Jogos Olímpicos. Rio de Janeiro: Zahar, 1997.

2. ADORNO, T e HORKHEIMER. M. Indústria Cultural - o esclarecimento como mistificação das massas. In: Dialética do esclarecimento. Rio de Janeiro: Zahar, 1996.

3. MORIN, E. Cultura de Massa no século XX - O espírito do tempo - Neurose. Rio de Janeiro: Forense Universitária, v. I, 1984.
} 
da de 30. Fatores de ordem socioestrutural são responsáveis pelo crescimento e consolidação dessa indústria, principalmente nos Estados Unidos. O surgimento de um grupo social consumidor, a classe média urbana assalariada, juntamente com a necessidade da expansão dos investimentos sem os riscos do mercado financeiro em crise, são o pano de fundo da emergência de uma terceira revolução industrial ${ }^{4}$. É a partir do conhecimento da dimensão do fenômeno midiático que entendemos a atenção dos teóricos da cultura sobre o tema, embora saibamos que as leituras não são uniformes. Até a década de 60, o tom da discussão versava sobretudo sobre a força e o caráter manipulador do pólo da produção cultural. Já a partir das décadas de 70/80, a ênfase nas pesquisas sobre a influência dos veículos midiáticos transfere-se para o pólo dos consumidores. Ou seja, as pesquisas posteriores e mais recentes aceitam a perspectiva de uma interação entre consumidores e produtores culturais, devolvendo aos sujeitos o poder de resistência frente aos estímulos da indústria cultural ${ }^{5}$. Um dos protagonistas dessa discussão é Edgar Morin. Ainda que problematize as contribuições dos frankfurtianos, oferece-nos uma leitura complementar, ao destacar o caráter dialético entre a produção dos sentidos individuais e coletivos. Todavia, para atualizar o debate e relativizá-lo, segundo o consumo dos grupos sociais, consideramos que a discussão que Bourdieu traça a respeito da indústria cultural apresenta-se, hoje, mais abrangente. Isto é, aproveita-se das teorias já propostas, reelaborando-as.

\section{REALIDADE CONTRADITÓRIA}

Adorno e Horkheimer ${ }^{6}$ desenvolvem uma reflexão especialmente crítica a respeito do fenômeno da mídia. Poderíamos afirmar que tal análise faz parte da teoria crítica da cultura, desenvolvida a partir da idéia da extrema racionalização tecnológica da sociedade moderna. Os autores apontam que a racionalização imposta pela sociedade administrada pela técnica não está presente apenas na esfera da vida econômica, mas vai além dela, e denunciam que a lógica do mercado passa a dominar os espaços da subjetividade e do espírito.

Embora, ao abordarem as características constitutivas do fenômeno da indústria cultural, os autores desenvolvam uma obra bastante extensa, destacaremos apenas alguns elementos que nos parecem essenciais para nosso argumento que, como veremos, irão se repetir na análise de Bourdieu. São eles: a dinâmica ideológica e manipuladora da técnica e da mensagem veiculada pela mídia; a indústria cultural como um sistema integrado e coerente de produção de bens espirituais; a perda da autonomia dos produtores e consumidores culturais; e a transformação dos bens culturais em mercadorias, portanto, seu caráter homogeneizado e totalizador.

Segundo os autores, a indústria cultural, 
embora apregoe estar a serviço dos sujeitos, democratizando e disseminando a cultura a todos, funciona, ao contrário, a partir de uma lógica própria. Isto é, seguindo a dinâmica da produção industrial competitiva, necessariamente tem que se adaptar à demanda dos mercados. A indústria dos espíritos, sujeita aos limites da expansão dos lucros, impõe tanto aos produtores quanto aos consumidores a perda da autonomia da criação. O ponto central da crítica é a denúncia de que as formações sociais modernas se transformam em sociedades administradas pela racionalidade técnica.

A tecnologia assume a forma de ideologia, presente em todas os espaços da convivência social, responsável pela crescente submissão dos indivíduos à lógica do mercado.

Produtores perdem seus instrumentos de produção e consumidores, inexoravelmente presos à ordem totalitária $\mathrm{e}$ uniforme das mercadorias, são incapazes de produzir sentido próprio frente ao consumo cultural. Para os autores, os bens espirituais, submetidos à dinâmica da produção em série, deixam de transcender o real, de rebelar-se ou propor uma reflexão para se constituírem como verdadeiros bens culturais; ao contrário, rendem-se a um adestramento que interdita o espaço da fantasia e do pensamento livre, impondo controles externos. Todos os bens espirituais produzidos em série homogeneizariam as mentes, alienariam e afastariam as possibilidades de resistência.

Por outro lado, Edgar Morin, relativizando as contribuições críticas de Adorno e Horkheimer, dá um outro tom à análise. Considera o fenômeno da cultura de massa como uma manifestação específica da sociedade moderna, esta vista como essencialmente policultural. Para ele, a cultura de massa alimentase dos sistemas simbólicos já existentes, possuindo um caráter profundamente integrador. Os valores e referenciais das culturas locais, religiosas e étnicas são reutilizados por ela, que apenas ordena e propõe uma forma de apropriação, jamais impõe. É contrário ao argumento da uniformização das mentes a partir do consumo generalizado e padronizado dos produtos culturais. É partidário da idéia de que o consumo é diferenciado, sempre. Embora a produção seja padronizada, em série e industrializada, a fruição ainda é prerrogativa dos sujeitos. O consumo é uma dimensão particularizada e, portanto, deve ser vista como uma forma individual de produção e articulação de sentido. Ao invés de trabalhar com a idéia de manipulação das mentes, Morin considera o fenômeno da cultura de massa um espaço a mais na vida dos indivíduos. Espaço para viverem a fantasia, o imaginário particular, resultados de experiências individualizadas. Segundo Morin, os aspectos que destacam a dimensão impositiva dos bens produzidos pela indústria cultural refletem uma falsa discussão. De fato o que se verifica é uma dialética constante entre produto do imaginário social e individual e os produtos propos- 
tos pela mídia. A dimensão estética, a utilização e fruição simbólica particularizada não estão interditadas.

É importante ressaltar que, embora as contribuições desses autores aparentem ser contraditórias, destacam a complexidade do fenômeno da indústria cultural. Embora os autores ofereçam material distinto de análise, apontam elementos definidores de um processo amplo e paradoxal que está presente em nosso cotidiano.

\section{VISÃO DE BOURDIEU}

Pela extensão da obra e pela variedade de assuntos que Bourdieu vem trabalhando, é estranho constatar a reduzida produção intelectual do autor sobre o fenômeno da indústria cultural. $\mathrm{O}$ livro Sobre a televisão, todavia, parece sinalizar uma preocupação mais sistematizada sobre o tema, embora, como está expresso logo em seu início, trate-se de uma reflexão pouco elaborada, sem apoio de trabalho empírico mais aprofundado.

O livro é resultado de uma compilação de textos nos quais Bourdieu se preocupa em atingir além do público acadêmico. A primeira parte constitui-se de duas palestras proferidas e televisionadas, em 1996, no Collège de France. Com uma linguagem mais coloquial, os textos iniciais fazem uma análise não exaustiva, portanto não acabada, sobre o tema, deixando em aberto algumas questões. A terceira parte constitui-se de textos ainda sobre o jornalismo, publicados na revista Actes de la Recherche en Sciences Sociales, e os Jogos Olímpicos, uma versão reduzida de outra palestra proferida em 1992. Embora o texto verse especificamente sobre a televisão, sua intenção é apreender a lógica de funcionamento do campo jornalístico ${ }^{7}$. Mais do que isso, versa sobre a influência crescente da televisão na produção da informação jornalística e na produção de outros bens culturais. É importante ressaltar, no entanto, que a contribuição de Bourdieu neste livro, embora possa parecer insuficiente, nos fornece pistas e elementos para traçar um paralelo com os autores acima mencionados.

Bourdieu inicia as palestras fazendo um alerta sobre os perigos do uso do jornal televisivo à democracia e à política na sociedade atual. Faz uma denúncia ao uso indiscriminado e pouco discutido deste instrumento de dominação. Diferente da visão frankfurtiana, não crítica a racionalidade técnica que envolve a produção da programação televisiva mas sim a manipulação ideológica a que todos estão sujeitos, produtores e consumidores, diante do império da concorrência. Para Bourdieu, o campo jornalístico está inserido no campo da produção cultural (educacional, literária, científica) e, tal como qualquer outro espaço de atuação social, funciona a partir de uma dinâmica própria, com certa autonomia.

7. O conceito de campo faz parte da obra de Bourdieu. Trata-se de uma noção que traduz a concepção social bourdiana. Espaço de relações entre grupos com distintos posicionamentos sociais. Espaço de disputa e jogo de poder. Segundo Bourdieu, a sociedade é composta de vários campos, vários espaços dotados de autonomia relativa e possuidores de regras próprias. O campo jornalístico é apenas um exemplo entre os vários subcampos que constituem o campo maior da cultura. Ao longo do texto esclareceremos a concepção do social em Bourdieu. 
Todavia, ressalta que o mundo do jornalismo apresenta ser o mais suscetível a uma dominação externa a seu próprio campo. Por estar estreitamente dependente dos níveis de audiência, compromete sua produção em função da ditadura do mercado ${ }^{8}$.

Bourdieu, ao fazer uma análise da televisão como instrumento de dominação, vai além de uma análise sobre o veículo. Faz simultaneamente uma denúncia da dinâmica da dominação inerente à sociedade de classes. Poderíamos afirmar que este livro veio complementar uma série de outros trabalhos do autor nos quais estão presentes os mecanismos sociais de reprodução da ordem e das hierarquias de poder. Tal como os frankfurtianos, afirma que, na indústria cultural, da qual a televisão é um exemplo emblemático, não há sujeito. Através de um discurso de aparência democrática, a informação veiculada pela televisão é formatada para agradar a todos, faz uso da despolitização dos conteúdos, do apelo às informações omnibus - para todos -, as quais Bourdieu define como: "fatos que, como se diz, não devem chocar ninguém, que não envolvem disputa, que não dividem, que formam consenso, que interessam a todo mundo, mas de um modo tal que não tocam em nada importante" .

\section{TELEJORNALISMO E AUDIÊNCIA}

O espaço televisivo ou informativo ao ser ocupado com determinados assuntos procede a uma lógica classificatória, ordenando os fatos segundo categorias de pensamento, segundo disposições engendradas pelo campo da concorrência. Portanto, a lógica da produção da notícia foge da sua esfera particular de criação para se submeter à esfera do mercado. A arte jornalística, na busca pela maior audiência, sujeita-se à dinâmica de transformar o ordinário da vida cotidiana em extra-ordinário. Daí o gosto acentuado da televisão e da prática jornalística por assuntos do dia-a-dia que tomam a forma de espetáculos. Assim, ao enunciarem o discurso do estar a serviço da democratização da informação, ao elegerem os sujeitos como protagonistas de suas produções, os responsáveis pela indústria cultural fazem uso de uma falsificação ideológica. Não estariam a serviço dos sujeitos, mas responderiam aos interesses econômicos de lucro das grandes corporações. Tal como Adorno e Horkheimer, Bourdieu afirma que a produção de bens culturais, para se adaptar à dinâmica do capitalismo, deve obedecer ao ritmo da competitividade, ou

\footnotetext{
8. Nota-se que tanto Bourdieu quanto os frankfurtianos, ao caracterizarem o fenômeno da indústria cultural fazem-no a partir de uma análise relacional. Ou seja, os elementos definidores do fenômeno não podem ser vistos de forma estanque ou isolados. Os elementos constitutivos fazem parte de uma concepção crítica da cultura, um conjunto teórico / conceitual coerente e sistematizado. Neste sentido, para ambos, é difícil falar de um elemento definidor do fenômeno sem remetê-lo aos demais. Todos estão relacionados e só tomam sentido quando remetidos uns aos outros.

9. BORDIEU, Pierre. Sobre a televisão. Op. cit. p. 23.
} 
seja, da concorrência por um público cada vez mais amplo. Nesse sentido, todos os indivíduos inseridos neste campo, sejam eles consumidores ou produtores, estariam envolvidos nesta lógica e não se aperceberiam disto. Envolvidas e adaptadas a esse esquema produtivo, as massas receberiam sem críticas as propostas vindas da programação.

Poderíamos afirmar que tanto os frankfurtianos quanto Bourdieu põem em discussão a questão da democratização dos bens da informação. Vão além ao dizer que, na busca de um público amplo, facilita-se o conteúdo, nivela-se por baixo a capacidade dos receptores, contribuindo, pois, para a falsa universalização das mensagens. Para facilitar a recepção, opta-se pela despolitização. Deixam-se de lado assuntos que podem surtir controvérsias, debates e/ou descontentamentos. Assuntos de fácil digestão e apropriação, pouco trabalhados, esvaziam os diálogos, a comunicação e a reflexão. Não contribuindo para a ampliação dos pensamentos, as informações produzidas pela lógica da indústria cultural tornam-se vazias de sentido. Dessa forma, além de se optar por mensagens fáceis, ocultam-se assuntos polêmicos para se conseguir maior audiência. $\mathrm{Na}$ busca de uma melhor performance, os produtores da informação alienam-se de seus instrumentos de criação, imitam seus concorrentes, espelham-se e pautam sua prática profissional em função da prática de seus adversários no mercado. O que se produz e faz sucesso é repetido por todos. A produção da informação é mais do que uma mercadoria, é fruto de uma produção homogeneizada e pasteurizada. Nada se acrescenta ao público, pois este fica sujeito à dinâmica interna, à disputa interna do campo que tem o monopólio da produção da informação.

Tão manipulados quanto manipuladores, os produtores culturais perdem sua autonomia. Pautando-se invariavelmente no modelo de sucesso, possuem pouca margem de atuação. A criação fica restrita aos limites impostos pela dinâmica da concorrência. Pior que a perda de autonomia, tais produtores alienam-se de sua capacidade de produção crítica e individualizada. Corpo de agentes fragmentado, os jornalistas têm em comum apenas a realidade da prática profissional, a busca do furo e do espetáculo. Estão de tal forma inseridos na dinâmica do campo que suas categorias de percepção estão voltadas e adaptadas para o jogo e a prática ali valorizada. Selecionam assuntos, impõem uma versão que sabem repercutirá bem. A busca do furo, da novidade, do espetacular é o que move o campo. Tarefa difícil, já que produzir o novo todos os dias, fazer do ordinário o espetacular, demanda muito trabalho. A lógica do mercado é manipuladora. Manipula produtores e consumidores, todos envolvidos na teia da audiência.

\section{DIFERENÇAS ENTRE OS TEÓRICOS}

Para um leitor pouco familiarizado com a obra de Bourdieu, seria correto classificar a leitura bourdiana sobre este veículo como frankfurtiana. Todavia, ainda que a primeira impressão seja essa, é importante afirmar que Bourdieu, tal como Morin, não partilha a idéia de uniformização e homogeneização do consumo dos bens culturais. Nestas palestras, 
especificamente com a intenção de apontar a dinâmica de funcionamento interno do campo jornalístico e televisivo, Bourdieu deixou de lado aspectos da apropriação das mensagens. Contudo, é sabido que, a partir de um outro enfoque, Morin e Bourdieu permitem ver o fenômeno da mídia como ambíguo e contraditório. A tendência a uma inexorável uniformização é relativizada por estes autores, que enfatizam a natureza diferenciada e hierarquizada entre os agentes sociais produtores e consumidores de bens culturais.

Para compreendermos a especificidade da contribuição de Bourdieu seria interessante considerar que este tem uma concepção sistêmica do social. A estrutura social é vista por ele como um sistema hierarquizado de poder e privilégio, determinado tanto pelas relações materiais quanto pelas relações simbólicas entre os indivíduos.

A diferente localização dos grupos sociais nessa estrutura deriva da desigual distribuição de recursos e poderes de cada um deles.

Bourdieu entende por recursos: capital econômico, capital cultural, capital social e capital simbólico. Assim, a posição que um determinado agente ocupa nessa geografia do social é definida, então, segundo a posição que esse mesmo agente ocupa nos diferentes campos ou fontes de poder. Ou seja, a posição ocupada por um grupo no campo social é definida de acordo com o volume e a composição de um capital adquirido e/ou incorporado.

Noutras palavras, para apreender concretamente as interações objetivas entre os indivíduos ou entre os grupos sociais, é preciso observar as relações entre as posições ocupadas segundo uma distribuição de recursos. A partir das diferentes posições ocupadas no espaço social, a realidade se apresenta então objetivamente como um sistema simbólico organizado segundo a lógica da diferença. O espaço social funciona como um espaço dotado de sentido e formado por estilos de vida variados e seus respectivos grupos de status. A desigual distribuição de capital econômico e cultural, que é própria da dinâmica da sociedade capitalista, permite a constituição de práticas e disposições culturais variadas e tipos específicos de interesse de grupos.

Nesse sentido, para compreender as diferenças e as semelhanças de disposições culturais dos indivíduos entre os grupos sociais, Bourdieu utiliza-se do conceito de habitus, o princípio orientador e unificador de todas as práticas. Ou seja, Bourdieu considera que as atividades e representações do agente social são explicadas por meio de um conjunto de disposições, éticas e estéticas, que expressam, na forma de sistemas de preferências culturais, as divisões derivadas da estrutura de distribuição das diferentes formas de capital ${ }^{10}$.

Desta forma, não é possível conceber, dentro do edifício teórico de Bourdieu, a idéia de um consumo uniforme e generalizado para todos os grupos sociais. As diferenças de origem social, mais especi-

10. ORTIZ, Renato (org.). Pierre Bourdieu. Coleção Grandes Cientistas Sociais. São Paulo: Ática, 1983. 
ficamente as diferenças de capital cultural acumuladas nas trajetórias dos grupos e dos indivíduos impedem a homogeneização das consciências.

No entanto, se essas afirmações distanciam Bourdieu da visão frankfurtiana aproximam-no de Edgar Morin. Este considera que os sistemas simbólicos, a partir de sua função de integração lógica e moral, são também reprodutores de consenso. $\mathrm{Na}$ qualidade de instrumentos de comunicação e conhecimento do mundo, os sistemas de símbolos da indústria midiática favoreceriam a comunhão de valores, o sentimento de pertencimento a grupos de estilos e vidas diferenciados.

Posto isso, é possível compreender as contribuições da Teoria Clássica no pensamento bourdiano sobre o fenômeno midiático. Não obstante, gostaríamos de ressaltar que Bourdieu sofistica a análise ideológica dos frankfurtianos e a análise da integração de Morin ao deslocar a discussão sobre as instâncias da indústria cultural a partir de uma nova concepção de cultura.

\section{PODER SIMBÓLICO PARA BOURDIEU}

Bourdieu afirma que a cultura ou os sistemas simbólicos podem ser concebidos de três maneiras. Primeiramente, como estruturas de orientação da ação, ou seja, como instrumentos de conhecimento e de construção do mundo dos objetos. Esta abordagem considera o mundo como um universo de trocas simbólicas onde a ação comunicativa se resumiria a um ato de interação passível de ser decifrado a partir do conhecimento de um código. Crê que a língua, a arte ou a religião são sistemas já estruturados, propriedade de todos, que podem usá-los igualmente. A segunda maneira de conceber a cultura é compreendendo-a como estruturas estruturadas como um código; salienta a natureza das equivalências entre sons e sentidos, passível também de ser utilizada por todos. Todavia, o uso de um conjunto de símbolos, como a língua, não se reduz à submissão passiva. O lento processo de aquisição de símbolos e referências culturais insensivelmente inculcadas pelas instâncias produtoras de bens simbólicos é resultado de uma experiência inconsciente ${ }^{11}$.

A família, a escola e mais recentemente a mídia, cada uma à sua maneira, imporiam, sem coerção ou consciência, um sistema integrado de padrões de comportamento e representações. Embora produtos de determinações sociais, os bens culturais e simbólicos produzidos submetem o agir e o pensar dos agentes de forma lenta e velada. Os sistemas simbólicos, assim concebidos, proporcionam uma concepção homogênea do mundo, do tempo e do espaço. Tornam possível o consenso. Símbolos, preceitos, ditados populares assim como a linguagem do cotidiano são instrumentos de integração do mundo. Enquanto instrumentos de conhecimento e de comunicação são responsáveis pelo consenso acerca do sentido do mundo social. A integração lógica é a condição da integração moral e da reprodução do social.

No entanto, indo além dessas duas formas de conceber os sistemas simbólicos, Bourdieu compreende também os sistemas culturais como instrumentos de dominação.

11. BOURDIEU, Pierre. O poder simbólico. Lisboa/Rio de Janeiro: Bertrand Brasil/Difel, 1989. 
Por exemplo, para ele a linguagem, como parte integrante da cultura, é mais que um instrumento de comunicação, é um instrumento de ação e poder. Todos os atos comunicativos, tais como os discursos e as mensagens, não estão destinados apenas a serem compreendidos e decifrados. São também signos a serem avaliados, signos de autoridade a serem obedecidos. Para ele, a prática lingüística comunica mais do que a informação declarada. Nesse sentido, alerta para a necessidade de se observar quem faz uso da fala, de onde fala e quando fala. $\mathrm{O}$ uso da linguagem tanto em seu estilo e forma como em seu conteúdo dependerá da posição ocupada por seu locutor.

\section{Todo discurso, para Bourdieu, deve ser visto dentro de um contexto social de produção e veiculação.}

Os discursos terão sempre um valor diferenciado, dependerão sempre da relação de forças entre os locutores concorrentes no mercado lingüístico.

Segundo o autor, aquele que tem o poder de falar em público sanciona sua fala como digna de existir, dá realidade a um discurso. A autoridade do sujeito que tem o poder da fala é uma autoridade quase mágica, pois objetiva e realiza o seu discurso. Tem legitimidade de impor um sentido e um conteúdo a todos. Portanto, não existem discursos neutros. Ao se conquistar o poder da fala, impõem-se simultaneamente as categorias de percepção, impõe-se também a estrutura de um pensamento, uma forma de perceber o mundo. Desta maneira, coloca como secundárias as funções de conhecimento ativo e integrador dos universos culturais e, ao tratar da terceira forma de conceber a cultura, privilegia as funções políticas dos sistemas simbólicos, apontando os usos da função de comunicação.

Para Bourdieu, todas as relações de comunicação são relações de força, relações de poder que dependem, na forma e no conteúdo, do poder material e simbólico acumulado pelos agentes envolvidos nessas relações. Reitera que exatamente pelo fato de os elementos culturais serem instrumentos de um conhecimento ativo e integrador - podem também cumprir a função ideológica e política de imposição de uma forma particular de conhecimento do mundo, isto é, uma forma particular de ver o mundo.

Neste sentido, a imposição do discurso daquele que tem o domínio ou o monopólio da fala traduz-se em um poder simbólico. Ou seja, o poder de inculcar formas e categorias de conhecimento do mundo, o poder de impor uma visão de mundo.

Segundo Bourdieu, o poder simbólico poderia ser definido como um poder invisível, o qual só pode ser exercido com a cumplicidade daqueles que não querem saber que estão sujeitos a ele ou mesmo que o exercem. Na forma de prestígio, reputação ou fama, o poder simbólico nada mais é do que a união dos outros tipos de poderes (econômico e cultural) ao se tornarem reconhecidos legitimamente ${ }^{12}$. 


\section{PODER DO TELEJORNALISMO}

No caso específico do discurso do telejornalismo, $o$ ato de emitir uma mensagem, acompanhada pela transmissão pública de imagens, recobre-se de uma aura divina, quase mágica, tem o poder de fazer existir aquilo que anuncia. O campo jornalístico tem o monopólio da produção da informação, detém o poder de criar fatos, dar existência e realizar seu discurso, impondo-o a todos. Seu efeito propriamente ideológico, portanto dissimulado, consiste na imposição de um sistema de classificação político sob a aparência legítima de categorias filosóficas e culturais. Para Bourdieu, os esquemas de percepção e classificação do telejornalismo obtêm sua força na relação de desconhecimento da manipulação; do poder mágico e arbitrário de fazer anunciar e existir um fato através de discursos e imagens. No entanto, não é qualquer um que tem o direito à fala. As mensagens são sempre emitidas por um agente dotado de autoridade, são sempre legitimadas por todo um corpo de agentes e instituições culturais. A docilidade frente ao arbitrário cultural instaura uma relação de dominação simbólica entre o sujeito do discurso e seus receptores. Instaura a crença no poder das palavras e naqueles que as pronunciam.

Para Bourdieu, o campo jornalístico é um campo sui generis. Ao mesmo tempo que tem o monopólio da informação, é parte constitutiva do campo da cultura no qual ocupa uma posição de pouco domínio. Deve esta situação ao fato de estar muito sujeito à lógica da concorrência e ter frágil autonomia. No entanto, aqueles que ocupam uma posição privilegiada no subcampo cultural do telejornalismo, são aqueles que detêm o poder material - conquistado pelos altos níveis de audiência - e o poder simbólico, retradução da legitimidade conferida pelo seu poder de vendagem. São porta-vozes da opinião pública, são reconhecidos por esta como tendo autoridade do poder da fala, da materialização de um fato, adquiriram o privilégio da criação.

Para Bourdieu, a dimensão ideológica do campo jornalístico é produto de um desconhecimento sistemático do arbitrário da produção cultural, do caráter mágico de sua criação e de sua legitimação. Ao criar, ao dar como existente um fato ou notícia, impõe suas categorias de percepção ao mundo, inculca uma visão de mundo. Contudo, alerta para mais um elemento de dominação. Considerando que o mesmo campo que tem o poder de criação e realização dos fatos do real está submetido a uma lógica que não lhe é própria, que sobrevive à custa da alienação de sua autonomia, conclui que a fabricação do real está submetida aos interesses do mercado.

Gostaríamos de concluir, não obstante, fazendo algumas considerações. Embora a análise atualizada sobre o poder ideológico da indústria cultural leve-nos a uma leitura pessimista da dinâmica da reprodução da dominação, seria importante pontuar que para Bourdieu todo conhecimento é uma forma de subversão. 


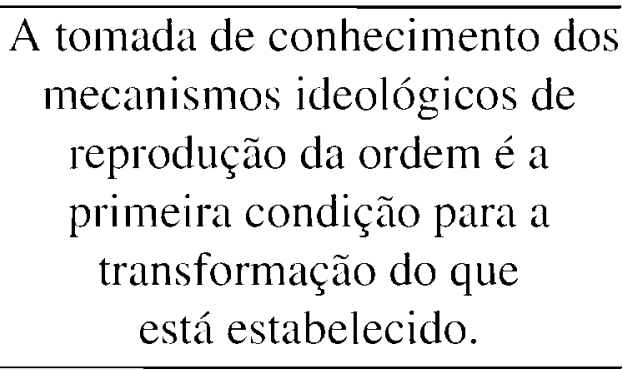

Resumo: Este artigo tem como objetivo fazer uma análise do livro de Pierre Bourdieu Sobre a televisão. Trata-se também de uma reflexão que traça um paralelo entre as contribuições deste autor com autores como Adorno/Horkheimer e Edgar Morin, na discussão sobre o fenômeno da indústria cultural. Consideramos que o livro Sobre a televisão é um resgate das leituras teóricas destes autores, atualizando-as ao nomear os mecanismos da dominação a partir do conceito de poder simbólico.

Palavras chaves: televisão, poder simbólico, indústria cultural, telejornalismo, Pierre Bordieu
As transformações políticas devem pressupor sempre uma subversão cognitiva, uma transformação da visão de mundo naturalizada pelos discursos oficiais. Para o autor, só mudaremos a realidade social na medida em que mudarmos a representação que temos dela. A ciência, como toda ação educativa comprometida com a ordem democrática, tem o papel de desvendar os instrumentos ocultos da dominação.

(Cultural industry: Bourdieu and the Classical Theory)

Abstract: This article aims at analyzing Pierre Bourdieu's book Sobre a televisão (About television). This reflection also traces a parallel between this author's contributions to classical theory authors, Adorno/Horkheimer and Edgar Morin, in discussing the cultural industry phenomenon. We consider the book Sobre a televisão a recovery of the theoretical reading of these authors, updating them by naming the domination mechanisms based on the symbolic power concept.

Key words: television, symbolic power, cultural industry, broadcast news, Pierre Bordieu 